\title{
Effects of Host Physiology on the Development of Core Rot, Caused by Alternaria alternata, in Red Delicious Apples
}

\author{
D. Shtienberg
}

Department of Plant Pathology and Weed Research, ARO, the Volcani Center, Bet Dagan, 50250, Israel. Accepted for publication 2 May 2012.

\begin{abstract}
Shtienberg, D. 2012. Effects of host physiology on the development of core rot, caused by Alternaria alternata, in Red Delicious apples. Phytopathology 102:769-778.

Alternaria alternata is the predominant fungus involved in moldy core and core rot of Red Delicious apples. The effects of environmental conditions during bloom on moldy core and core rot, and on the need for fungicide application, were examined in 10 experiments carried out in 2007. In untreated experimental plots, typical moldy core symptoms were very common, with relatively low variability (coefficient of variation: $22.2 \%$ ) among experiments; core rot incidence ranged from 2 to $26 \%$ with large variability (coefficient of variation: 90.0\%) among experiments. No evidence of prevailing environmental conditions during bloom affecting the development of moldy core or core rot was detected. No effect of fungicide application (a mixture of bromuconazole + captan
\end{abstract}

ABSTRACT three times a week at bloom) on moldy core or core rot was found. A random distribution of moldy core and an occasional aggregation of core rot in the orchards were indicated from Morisita's index of dispersion $\left(I_{\delta}\right)$. The hypothesis that core rot incidence is governed by host physiology and that yield load can be used as an indicator of trees' susceptibility was examined in a set of eight observations and four experiments. No correlation was found between tree yield load and moldy core, but core rot incidence was inversely related to yield load. Furthermore, irrespective of tree yield load, core rot was more abundant on large compared with small fruits. It is concluded that host physiology, rather than pathogen occurrence or environmental conditions at bloom stage, governs the development of core rot in Red Delicious apples caused by A. alternata in Israel.

Additional keywords: apple disease, moldy core disease.
Apple (Malus domestica Borkh) is the largest deciduous crop under cultivation in Israel, and 'Red Delicious' constitutes about one-third of the total production area. A high proportion of Red Delicious apples exhibit some form of colonization by microorganisms within the core region. The term moldy core has been used to describe a situation in which fungal mycelium is evident within the loculus (the ovary or seed cavity) without penetration into the mesoderm (flesh) of the apple. If invasive penetration into the mesoderm occurs, the resulting rot is commonly described as core rot $(1,16)$. Much of the published literature refers to any fungal presence (whether invasion of the mesoderm occurs or not) as moldy core. The term moldy core is therefore imprecise. In this study we followed the definitions used by Little and Holmes (16): core rot refers to a pathogen entering the mesoderm; the presence of fungal mycelium in the loculus is considered a noninvasive moldy core and therefore, it is not core rot. A complex of fungi may cause moldy core, core rot or both, including Stemphylium, Cladosporium, Ulocladium, Epicoccum, Coniothyrium, Penicillium spp., Pezicula malicorticis, Pezicula alba, Mucor, Fusarium, and others. The most commonly isolated fungus, however, is Alternaria alternata (Fr.) Keissler $(1,3-7,8,10,29,30)$ and in Israel this fungus has repeatedly been considered as the predominant pathogen $(20,22-25)$.

Core rot is characterized by dark brown tissue that appears dry and corky within the seed loculi and contains air pockets when it penetrates into the fruit mesoderm. The rot may be either a slow, dry rot confined to the mesoderm adjacent to the core or a wet rot that progresses more rapidly and deeply into the mesoderm tissue. External symptoms on the fruit are quite subtle, and the disease

Corresponding author: D. Shtienberg; E-mail address: danish@ volcani.agri.gov.il

http://dx.doi.org/10.1094/PHYTO-09-11-0260

(C) 2012 The American Phytopathological Society typically goes unnoticed until the fruit is cut open. In some cases, external symptoms of infection may include premature ripening and fruit drop $(3,22,24,30)$. Core rot in Red Delicious, associated with $A$. alternata, has been responsible for significant economic losses in Israel. The incidence of diseased fruits, according to samplings from packing houses in northern Israel, averages from 3 to $10 \%$, but in some years there has been a significant increase in disease incidence, such as in 2003 when it reached up to $40 \%$ in some orchards $(20,22,25)$. In general, harvests that are affected by core rot with an incidence exceeding $8 \%$ can only be sold for industrial use at low prices. However, even lower incidence of fruits exhibiting core rot has the potential to affect the reputation of Red Delicious apples. The development of management strategies enabling suppression of core rot in Red Delicious apples is of great importance to the apple industry in Israel and elsewhere.

The essential requirements for infection are a susceptible host, adequate primary inoculum and suitable environmental conditions, allowing spores to germinate and infect the host. Red Delicious apples have an open calyx, a developmental phenomenon in which the stigma and style of the blossom form an open channel, which runs from the calyx end of the fruit into the core. The open calyx allows colonization of the core area of the developing fruit by various fungi and bacteria. A. alternata, which colonizes senescing flower parts of the Red Delicious apple during and shortly after bloom, moves (presumably through the open calycine tube) into the receptacle or core region of the fruit $(4,6,7,17,20,21,25,29)$. Infections are favored by frequent rains, prolonged periods of high relative humidity and temperatures ranging from 10 to $25^{\circ} \mathrm{C}$ that prevail during bloom (30). Fluctuations in weather at this development stage are considered to be one of the factors leading to the variability in the incidence of moldy core and core rot among regions and years. Colonization of the loculus by A. alternata ultimately results in the development of moldy core. For core rot to develop, the pathogen colonizing 
the loculus must penetrate the seed locule walls and invade the mesoderm. This usually happens at advanced stages in fruit development. Consequently, reducing blossom infection and loculus colonization is likely to reduce the incidence of core rot. One way of achieving this goal is to apply fungicides at bloom stage.

The efficacy of numerous fungicides applied at bloom has been examined over the years, with variable results. In some studies, attempts to control core rot have failed $(3,6,10)$ or were unsatisfactory (4). However, significant reductions in core rot have been reported as well, for example in Tasmania, by applying two benomyl and iprodione sprays during the full-bloom stage (1) or in Israel, by applying difenoconazole or bromuconazole with captan at the pink-cluster stage, $60 \%$ bloom and full bloom (23). Nevertheless, results were variable in these studies as well, with core rot reduction ranging from 45 to $80 \%$ compared with untreated control trees $(22,23,25)$. The reasons for such inconsistent results are unknown. One possibility is that blossoms that were unopened at the time of spraying, and therefore were unprotected by the fungicide, were infected when opened and exposed to weather conditions that favored the pathogen.

Highly effective fungicides against $A$. alternata are available $(22,23)$, and we therefore hypothesized that the factor hindering satisfactory disease control is improper timing of spraying. Accordingly, our first objective was to determine the effects of environmental conditions during bloom on moldy core and core rot and on the need for fungicide application, by carrying out 10 experiments in 2007. Although it was not our original intent, analyses of the results provided insight into the spatial distribution of the disease in naturally infested orchards and gave rise to a new hypothesis that factors related to host physiology (as indicated by yield load and fruit size), rather than environmental conditions, govern the incidence of fruits exhibiting core rot. The association between core rot and fruit load has been mentioned in several publications (1) and on some websites (for example, New Mexico State University; http://aces.nmsu.edu), but we could not find any experimental evidence to support the observation. Accordingly, the second objective of this study was to determine the relationships between yield load or fruit size and the incidence of moldy core and core rot in naturally infected orchards. This hypothesis was examined in a set of observations and experiments performed between 2008 and 2010 in commercial orchards.

\section{MATERIALS AND METHODS}

Effects of environmental conditions during bloom on moldy core and core rot and on the need for fungicide application. Data recorded in a previous study were used to develop criteria to predict the likelihood of core rot in Red Delicious apples (D. Shtienberg, unpublished data). It was found that the incidence of core rote was very low $(<1.5 \%)$ when minimum temperature, maximum temperature, and the duration of wetness were $<6^{\circ} \mathrm{C}$, $<14.5^{\circ} \mathrm{C}$, and $<10 \mathrm{~h}$, respectively. The incidence of core rot was low $(1.5$ to $4 \%)$ when these values were $>6^{\circ} \mathrm{C},<14.5^{\circ} \mathrm{C}$, and 8 to $10 \mathrm{~h}$, respectively. Intermediate core rot incidence (4.1 to $8 \%$ ) occurred when these values were $>6^{\circ} \mathrm{C},<14.5^{\circ} \mathrm{C}$, and 10 to $13.5 \mathrm{~h}$, and severe core rot incidence $(>8.1 \%)$ occurred when these values were $>6^{\circ} \mathrm{C},>14.5^{\circ} \mathrm{C}$, and $>13.5 \mathrm{~h}$, respectively. In 2007, 10 experiments (coded E1 to E10; Table 1) were carried out in commercial orchards to examine the possibility of using these criteria for timing fungicides for core rot management. These experiments were carried out in commercial orchards located in the Galilee, Hula Valley, and Golan Heights regions of Israel, where the disease had been frequent in previous years. Fertilization, irrigation and other cultural practices were as recommended to commercial growers by the Extension Service of the Israeli Ministry of Agriculture and Rural Development. Alfanol Super (naphthalene acetic acid; Tapazol Chemical Works, Ltd., Beit Shemesh, Israel) was applied at a rate of 50 to $60 \mathrm{ppm}$ prior to harvesting. To achieve a wide range of environmental conditions among experiments, the selected sites differed in distance

TABLE 1. Details of the experiments and observations undertaken in commercial orchards between 2007 and 2010

\begin{tabular}{|c|c|c|c|c|c|c|c|}
\hline \multirow[b]{2}{*}{ Year } & \multirow[b]{2}{*}{ Purpose } & \multirow[b]{2}{*}{ Code $^{\mathrm{z}}$} & \multirow[b]{2}{*}{ Region } & \multicolumn{3}{|c|}{ Experimental site } & \multirow[b]{2}{*}{ Variety } \\
\hline & & & & Latitude (deg. min s) & Longitude (deg. min s) & Altitude (m) & \\
\hline \multirow[t]{12}{*}{2007} & \multirow{12}{*}{$\begin{array}{l}\text { Environmental conditions } \\
\text { and fungicide effects }\end{array}$} & E1 & Western Galilee & 330250 & 352404 & 800 & Top Red \\
\hline & & E2 & Upper Galilee & 330115 & 352404 & 800 & Top Red \\
\hline & & E3 & Upper Galilee & 330358 & 352704 & 680 & Top Red \\
\hline & & E4 & Upper Galilee & 330718 & 353235 & 400 & Top Red \\
\hline & & E5 & Hula Valley & 331712 & 353422 & 495 & Top Red \\
\hline & & E6 & Golan Heights & 330944 & 354325 & 810 & Top Red \\
\hline & & E7 & Golan Heights & 330954 & 354808 & 1,020 & Top Red \\
\hline & & E8 & Golan Heights & 330734 & 354815 & 940 & Top Red \\
\hline & & E9 & Golan Heights & 330624 & 354834 & 970 & Top Red \\
\hline & & E10 & Golan Heights & 325711 & 355220 & 730 & Top Red \\
\hline & & E3-B & Upper Galilee & 330358 & 352704 & 680 & Top Red \\
\hline & & E10-B & Golan Heights & 325711 & 355220 & 730 & Top Red \\
\hline 2008 & Yield load: alternate bearing & O1 & Golan Heights & 330618 & 354902 & 960 & Top Red \\
\hline \multirow[t]{2}{*}{2009} & \multirow[t]{2}{*}{ Yield load: alternate bearing } & O1-B & Golan Heights & 330618 & 354920 & 960 & Top Red \\
\hline & & $\mathrm{O} 2$ & Golan Heights & 330716 & 354822 & 950 & Oregon Spur \\
\hline \multirow[t]{12}{*}{2010} & \multirow[t]{8}{*}{ Yield load: alternate bearing } & $\mathrm{O} 1-\mathrm{C}$ & Golan Heights & 330618 & 354920 & 960 & Top Red \\
\hline & & $\mathrm{O} 2-\mathrm{B}$ & Golan Heights & 330716 & 354822 & 950 & Oregon Spur \\
\hline & & $\mathrm{O} 3$ & Golan Heights & 330954 & 354808 & 1,020 & Scarlet \\
\hline & & $\mathrm{O} 4$ & Golan Heights & 330624 & 354834 & 960 & Top Red \\
\hline & & O5 & Golan Heights & 330734 & 354815 & 940 & Oregon Spur \\
\hline & & O6 & Golan Heights & 325730 & 355224 & 740 & Super Chief \\
\hline & & $\mathrm{O} 7$ & Upper Galilee & 330358 & 352704 & 680 & Top Red \\
\hline & & O8 & Upper Galilee & 330330 & 352024 & 700 & Top Red \\
\hline & \multirow[t]{4}{*}{ Yield load: thinning } & E11 & Golan Heights & 330622 & 354834 & 970 & Top Red \\
\hline & & E12 & Golan Heights & 330734 & 354815 & 940 & Oregon Spur \\
\hline & & E13 & Golan Heights & 330911 & 354648 & 970 & Oregon Spur \\
\hline & & E14 & Golan Heights & 330657 & 354808 & 990 & Scarlet \\
\hline
\end{tabular}

${ }^{\mathrm{z}} \mathrm{E}$, replicated experiment; $\mathrm{O}$, orchard observation. 
from the Mediterranean Sea (10 to $70 \mathrm{~km}$ ), altitude (400 to 1,020 $\mathrm{m}$ above sea level), annual rainfall (average for the last decade ranging from 450 to $810 \mathrm{~mm}$ ) and rainfall in April, the time of blooming ( 23 to $50 \mathrm{~mm}$ ). All experimental sites were located at a distance of $<1 \mathrm{~km}$ from a standard weather station.

Each experiment consisted of several treatments, as follows. In treatment 1, trees were not sprayed with fungicide against $A$. alternata at all (untreated control). In treatment 2, attempts were made to protect all open blossoms; thus, spraying was initiated at the first open blossom stage and continued, three times a week, until petal drop. The number of sprays applied in that treatment in the different experiments ranged from six to nine (mean \pm SD: $7.3 \pm 0.2$ sprays). In treatment three sprays were applied at the pink-cluster stage, $60 \%$ bloom and full bloom as suggested by Reuveni and Prusky (23). In treatments 4 to 6 , the above criteria were used for timing sprays which were applied when temperature and wetness in the previous day were expected to induce low, intermediate, or high core rot incidence, respectively. The minimal interval between sprays in these treatments was 2 days. The number of sprays applied in treatment 4 in the different experiments ranged from 0 to 3 (mean \pm SD: $1.3 \pm 0.2$ sprays), in treatment 5 from 0 to 2 (mean \pm SD: $0.8 \pm 0.2$ sprays), and in treatment 6 from 0 to 1 (mean \pm SD: $0.3 \pm 0.1$ sprays). In all treatments of all experiments, a mixture of the systemic DMI fungicide bromuconazole (Vectra, 100 SC, Aventis, France; 0.08\%, vol/vol) and the protectant fungicide captan (Merpan, $50 \mathrm{WP}$, MakteshimAgan, Israel; $0.25 \%$, vol/vol) was applied to runoff by means of a gun sprayer, at a volume of 1,200 to 1,500 liter/ha, according to tree size and number of open blossoms at spraying. As described in the Results section, fungicides had no effect on the incidence of moldy core or core rot, thus, the results of treatments 3 to 6 are not presented in this report. The experiments were laid out in completely randomized or randomized block design with four or five replicates each. The size of each experimental plot was four or five trees along the row. The distance between trees within rows was 1.2 to $2.5 \mathrm{~m}$ and 4 to $4.5 \mathrm{~m}$ between rows.

Two additional experiments were carried out in sites 3 and 10 (coded E3-B and E10-B; Table 1). The aim of these experiments was to examine whether core rot is intensified under conditions that are assumed to be conducive to the pathogen. Each experiment consisted of two treatments. Treatment 1 was an untreated control. In treatment 2, sprinklers were installed above the canopy of the trees and operated for $14 \mathrm{~h}$ on the night of 22 April 2007, when the trees were in full bloom and the minimum temperature was forecasted to be above $15^{\circ} \mathrm{C}$. These experiments were laid out in randomized block design with four replicates; experimental plots were not sprayed with fungicides for the suppression of $A$. alternata. Just before harvest, 25 fruits were randomly collected from the central two trees in each replicate plot, from all experiments, and brought to the laboratory; the outer trees serving as barriers in each experimental plot. Each fruit was cut in half longitudinally, inspected visually and graded according to the following 3-point scale: 1, fruits without any visible symptoms of moldy core or core rot; 2 , fruits with evident fungal mycelium colonizing the loculus (at any level) without penetrating into the mesoderm; and 3, fruits with typical rotting symptoms (at any level) in the mesoderm. The incidences (\%) of fruits with moldy core (grade 2) or core rot (grade 3) were calculated for each experimental plot; treatment averages were then computed based on the replicates values.

Correlations were sought between weather records (independent variables) and incidence of moldy core or core rot (dependent variables). Hourly data were used to calculate daily records (for example, daily minimum or maximum temperatures, rain, duration of wetness, temperature during the wet period), as well as averages or accumulated records (for example, bloom-long average temperature or accumulated rainfall). Analyses included data recorded from 2 weeks before bloom until 1 month after termination of blooming. Single weather data were examined first, followed by combinations of two or more variables (e.g., minimum temperature and wetness duration).

Spatial distribution of moldy core and core rot. The Morisita index of dispersion $\left(I_{\delta}[19]\right)$ was used to determine whether moldy core and core rot were distributed at random or in aggregates in the experimental sites. In each experiment, experimental plots were used as quadrants and $I_{\delta}$ was calculated according to the formula $I_{\delta}=n\left\{\left[\left(\sum_{i} x_{i}^{2}\right)-\Sigma_{i} x_{i}\right] /\left[\left(\sum_{i} x_{i}\right)^{2}-\Sigma_{i} x_{i}\right]\right\}$ where $n$ is the number of quadrants and $x_{i}$ is the number of fruits with moldy core or core rot in quadrant $i(i=1 \ldots n)$. $I_{\delta}$ values have three different interpretations: $I_{\delta}<1.0$ indicates a uniform distribution; $I_{\delta}=1.0$ indicates a random distribution, and $I_{\delta}>1$ indicates an aggregated distribution (19). $I_{\delta}$ values enable detecting a statistically significant departure from random distribution $\left(I_{\delta}=1.0\right)$ by comparing $F_{0}$ values with the values of $F_{\infty}{ }^{n-1}(\alpha)$ according to Morisita's method (19): $F_{0}=\left[I_{\delta} \times(N-1)+n-N\right] /(n-1)$, where $n$ is the number of quadrants and $N$ is the total number of fruits with moldy core or core rot $\left(=\Sigma_{i} x_{i}\right)$. When $I_{\delta}$ values did not significantly differ from 1.0, the distribution of fruits with moldy core or core rot was considered random; when $I_{\delta}$ values were significantly greater than 1.0, the distribution of fruits with moldy core or core rot was considered aggregated.

Relationship between yield load or fruit size and the incidence of moldy core and core rot. About 1 month before commercial harvest in summer 2008, 20 trees growing in a commercial orchard (observation coded $\mathrm{O} 1$; Table 1), were selected based on their fruit load. The trees were located in the same rows, growing side by side and were comparable in dimension and vigor. Trees were assigned to two groups reflecting their natural alternate bearing habit: trees bearing a light yield and those bearing a heavy yield. As we deliberately chose trees with light and heavy yield load, they do not represent the average yielding capacity of the trees in that orchard. Right before commercial harvest, 100 fruits were randomly harvested from each of the trees. Fruits were cut individually and graded using the aforementioned scale. In addition, the size of each fruit was recorded based on the following criteria: 'small' if their weight was $<65 \mathrm{~g}$ and their diameter was $<120 \mathrm{~mm}$ or 'large' if their weight was $>70 \mathrm{~g}$ and their diameter was $>140 \mathrm{~mm}$. Data were used to calculate the incidence of fruits with moldy core or core rot (in $\%$ ), and the proportion of small or large fruits per tree and per group. In the following 2009 and 2010 seasons, 100 fruits were sampled from the same trees, weighed, cut, and observed visually as described above (observations O1-B and O1-C; Table 1). Then, all fruits remaining on the trees were harvested. Summing the weight of the sampled 100 fruits and the weight of the remaining fruits resulted in the total yield load (in $\mathrm{kg}$ ) of each tree.

In the summer of 2009 , the same procedure was repeated in another orchard (observation O2; Table 1). There, 40 trees were selected and assigned to two groups: trees bearing light and heavy yields, respectively. Fruit sampling, yield estimation and disease evaluation were carried out as described above. The same 40 trees were sampled once again in 2010 (observation O2-B; Table 1). To determine whether the results obtained in these two observations represent a general phenomenon, additional observations were carried out in 2010 in six commercial orchards located at geographically dissimilar sites (observations O3 to O8; Table 1). In each observation, 12 to 20 trees were selected based on their fruit load and assigned to the light and heavy yield groups. Fruit sampling and yield estimation were carried out as described above.

In all observations, differences in fruit load reflected the natural alternate yield bearing (i.e., year-to-year fluctuation in fruit load). In addition, attempts were made to artificially induce variations in yield among trees. Four experiments were performed in 2010 (experiments E11 to E14; Table 1) in commercial orchards. In each orchard, 25 trees bearing many fruitlets were selected and 
marked about a month after full bloom, when the fruitlets were 25 to $30 \mathrm{~mm}$ in diameter. The trees were located in the same rows, growing side by side, and were comparable in dimension and vigor. Trees were randomly assigned to 5 groups (treatments). In treatment 1, 50 fruitlets were marked with colored plastic bands and the other fruitlets were thinned. In treatment 2, 100 fruitlets were marked and left on the tree; in treatment 3, 200 fruitlets were marked and left on the tree; in treatment 4, 300 fruitlets were marked and left on the tree; and in trees assigned to treatment 5, all fruitlets (ca. 500) were left on the tree. There were five replicates (trees) per treatment and the experiments were arranged in completely randomized design. In each experiment, fruit sampling and yield estimation were carried out as described above.

To examine whether fruit size affects the incidence of core rot, we quantified the relationship between the proportion of large fruits and the relative incidence of large fruits with core rot, and the relationship between the proportion of small fruits and the relative incidence of small fruits with core rot. The proportion of large (or small) fruits was calculated based on the number of large (or small) fruits in each sampling of 100 fruits. The relative incidence of large (or small) fruits with core rot was calculated with respect to the proportion of large (or small) fruits in the sample. For example, if 60 of the 100 sampled fruits were large, the incidence of large fruits in that sample was $60 \%$. If 15 of the large fruits had core rot, then the relative incidence of large fruits with core rot was $25 \%(15 / 60 \times 100)$. The proportion of large (or small) fruits and the relative incidence of large (or small) fruits with core rot were initially calculated for individual trees and then for each group or treatment in the observations and experiments carried out in 2009 and 2010.
Data analysis. Differences in the incidence of moldy core or core rot, or in yields between groups of trees in the observations and among treatments in the experiments were examined by logistic regression or ANOVA test at $P \leq 0.05$, as appropriate. Recorded percentages were arcsine transformed before analysis. Data recorded in the thinning experiments were analyzed using mixed model where the thinning treatments were considered as fixed factors; 'experiment' and 'replications (experiments)' were used as random factors in the analysis. General linear model, linear and nonlinear regression analyses were used to quantify the relationships between weather variables and moldy core or core rot incidence. Nonlinear regression was used to quantify the relationship between yield load and the incidence of core rot. Statistical analyses were performed using JMP software (SAS Institute Inc., Cary, NC).

\section{RESULTS}

Effects of environmental conditions during bloom on moldy core and core rot and on the need for fungicide application. Visual mold symptoms were observed in the seed locules of 37 to $78 \%$ (mean $57.1 \pm 13 \%$ ) of the fruits sampled from the untreated experimental plots. Variation in moldy core incidence among the 10 experiments was relatively low (variance of $22.2 \%$ ). Core rot incidence ranged from 2 to $3 \%$ in experiments E1, E6, E8, and E9, to 24 and 26\% in experiments E4 and E5 (mean $9.8 \pm$ $8.8 \%$ ) (Fig. 1), and variation in core rot incidence among the 10 experiments was high (variance of 90.0\%). The correlation between the incidence of moldy core and core rot in specific experiments and in overall analysis of the data was insignificant (data not shown). Thus, high incidence of core rot was
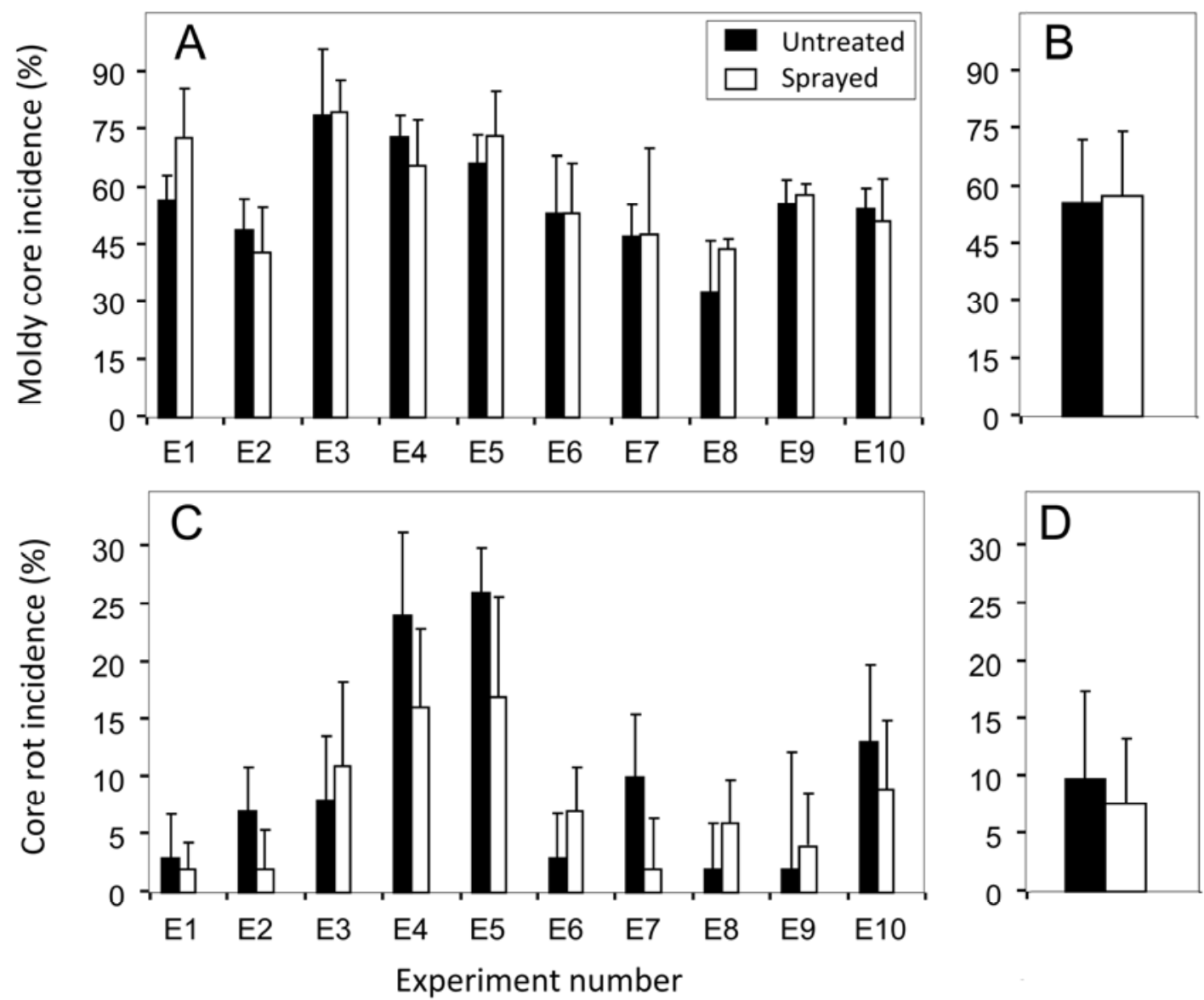

Experiment number

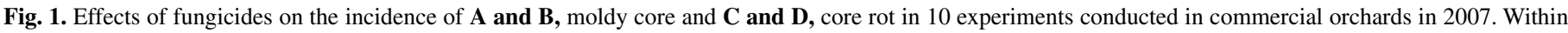

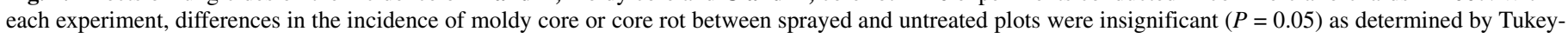
Kramer protected honestly significantly different test. B and D, Average values for the 10 experiments. Vertical bars represent the standard deviation of the mean. 
not necessarily associated with high incidence of moldy core, and vice versa.

Our initial assumption was that $A$. alternata infects the blooms and severe infections are associated with favorable weather conditions during bloom. However, attempts to find any correlation between weather parameters and incidence of moldy core or core rot did not result in any conclusive findings. An example is given in Figure 2 for wetness and temperature data recorded at the weather stations located near experiments E3 and E4 sites: wetness during bloom was more abundant and temperatures were, in general, higher at the site of experiment E3, and more rain fell at that site as well (20.2 and $14.0 \mathrm{~mm}$ for experiments E3 and E4,
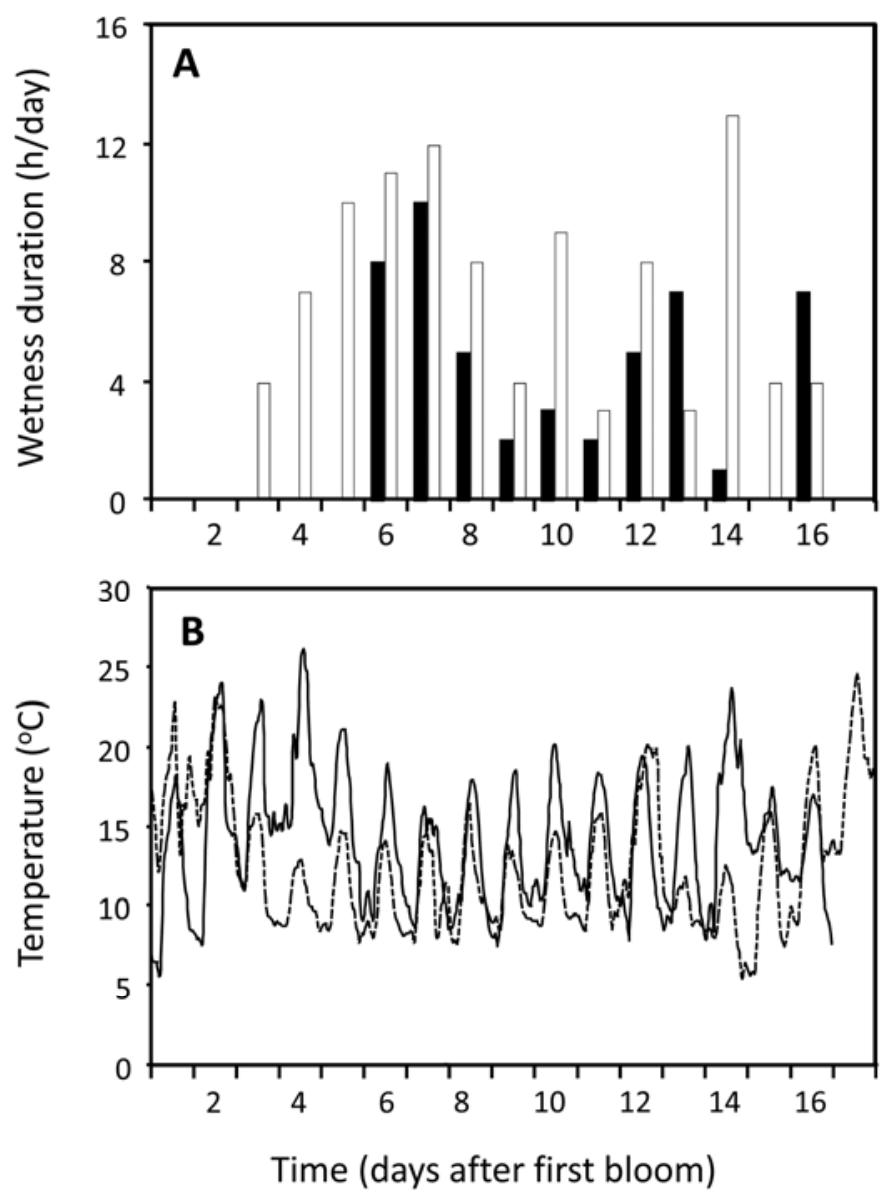

Fig. 2. A, Wetness duration and $\mathbf{B}$, temperature recorded at weather stations located near the sites of experiment E3 (open bars and filled line) and experiment E4 (filled bars and broken line) during bloom. respectively). Presumably, the environmental conditions during bloom at the site of experiment E3 were more suitable for the pathogen than those at the site of experiment E4. Nevertheless, core rot incidence in experiment E4 was three times higher than in experiment E3 (24 and 8\%, respectively; Fig. 1). Analyses of weather data recorded pre- and post-bloom during fruitlet development also gave inconclusive results. Wetting of the blossoms in experiments E3-B and E10-B did not affect the incidence of core rot significantly (at $P=0.05$ ): in the treatments with sprinklers installed to wet the blossoms, the incidence of core rot was 4.9 and $9.3 \%$ compared with an incidence of 8 and $12.7 \%$, respectively, in plots where sprinklers were not installed.

Frequent application of fungicides during bloom had no effect on moldy core or core rot incidence, and differences among sprayed and nonsprayed plots were insignificant $(P=0.05)$ in all experiments. The average incidence of moldy core in the sprayed plots across all experiments was $59.3 \pm 13.2 \%$, and the incidence of core rot was $7.6 \pm 5.6 \%$ (Fig. 1). Furthermore, in all experiments, differences in moldy core or core rot incidence among the other fungicide treatments included in the experiments, and between these treatments and the untreated control, were insignificant at $P=0.05$ (data not shown).

The incidence of moldy core and core rot varied markedly among experimental plots in the same experiments. An example is presented in Figure 3 for data recorded in experiment E1. As fungicide spraying did not affect the disease, specific treatments are not indicated in the figure, only their location in the five (plots) by four (rows) layout. Variation in the incidence of moldy core among experimental plots was low, ranging from 52 to $76 \%$ (mean $64 \pm 9 \%$ ) with variance of $14.1 \%$. Core rot incidence in these plots ranged from 0 to $14.7 \%$ (mean $3.4 \pm 4.5 \%$ ) with a variance of $133.7 \%$ (Fig. 3). The Morisita index of dispersion $\left(I_{\delta}\right)$ was then used to determine the spatial distribution of the disease in each of the 10 experiments. For moldy core (grade 2 of the assessment scale), $I_{\delta}$ values ranged from 0.99 to 1.06 in the 10 experiments and none of the $I_{\delta}$ values differed significantly from 1.0 (at $P=0.05$ ). Accordingly, the distribution of trees with moldy core fruits in these orchards was defined as random. For core rot (grade 3 of the assessment scale), $I_{\delta}$ values ranged from 1.13 to 2.62 in the 10 experiments and all $I_{\delta}$ values were significantly greater than 1.0 (at $P<0.05$ ). Accordingly, the distribution of trees with core rot fruits in these orchards was defined as aggregated.

Relationships between yield load or fruit size and incidence of moldy core and core rot. Core rot incidence in specific trees fluctuated among years: trees bearing fruits with high core rot incidence in 2008 had low core rot incidence in 2009 and high incidence again in 2010. Similarly, trees bearing fruits with low core rot incidence in 2008 had high core rot incidence in 2009
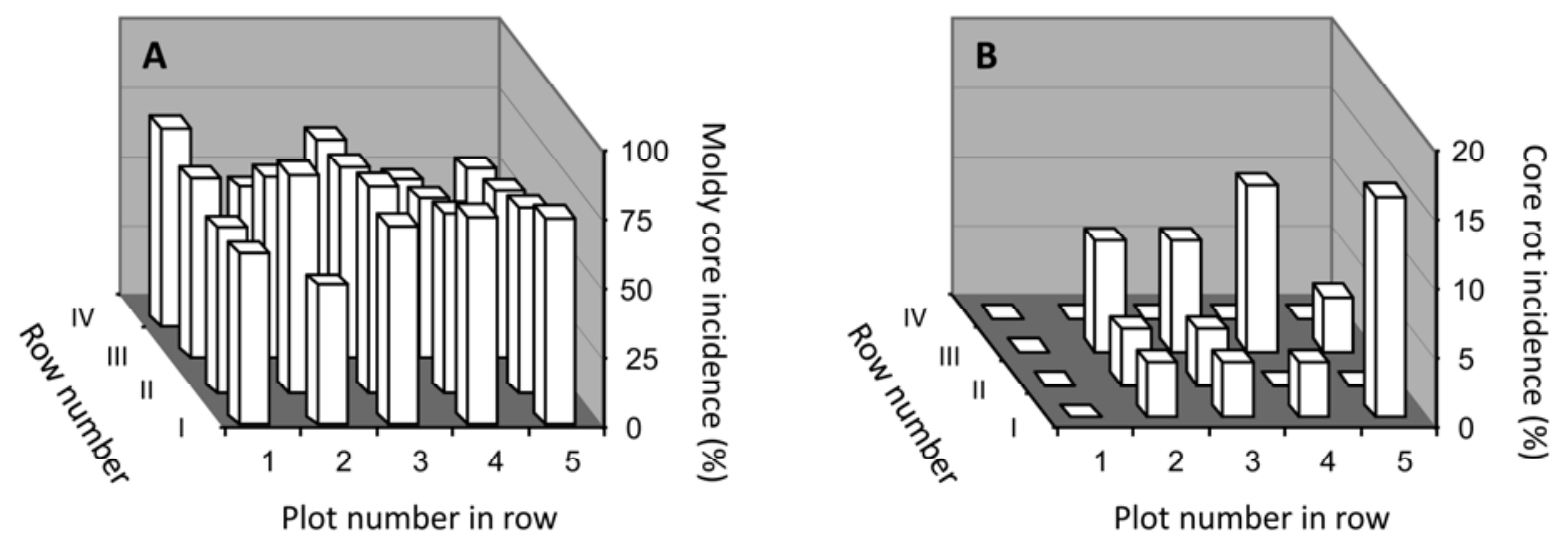

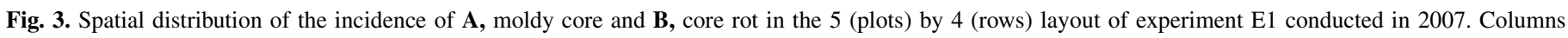
represent the incidence of moldy core or core rot in each experimental plot. 
and low incidence again in 2010 (Fig. 4). In any given year, core rot incidence was inversely related to yield, in line with these trees' alternate bearing habit. This phenomenon occurred naturally and was recorded in two separate orchards over 2 or 3 years (Fig. 4). To determine whether the converse levels of core rot and yield load observed in these two orchards is a general phenomenon, additional observations were carried out in 2010 in six commercial orchards located at sites with dissimilar conditions. In each orchard, trees were selected based on their expected yield load (light or heavy). In all observations, differences in the incidence of moldy core between light-cropping trees and heavycropping trees were insignificant. However, in five out of the six observations, core rot incidence was significantly lower in heavycropping trees than in the light-cropping ones (Fig. 5).

In the above observations, differences in yield between lightand heavy-cropping trees occurred naturally, as part of the alternate bearing of yield on these trees. In a series of four experiments, we attempted to deliberately induce yield variation by fruitlet thinning among treatments. In general, thinning did not affect the incidence of moldy core, but it had a significant effect on core rot incidence in three out of the four experiments: the more rigorous the thinning (and the lower the yield), the higher the incidence of core rot (Table 2, Fig. 6). Results of the described experiments and observations suggested that the incidence of core rot is inversely related to yield. Thus, data recorded in the 15 experiments and observations carried out in 2009 and 2010 were analyzed together. A highly significant $(P<0.0001)$ exponential decay relationship between the incidence of core $\operatorname{rot}(Y$, in \%) and yield load $(X$; in $\mathrm{kg} /$ tree) was observed in 12 of the 15 experiments and observations. The regression equation was $Y=0.5 \times$ $e^{(178 /(X-56.0))}$. Data recorded in three orchards (experiment E14, observation $\mathrm{O} 4$ and observation $\mathrm{O} 7$ ) did not fit well with the general regression equation; nevertheless, these data points fit a similar exponential decay equation with different coefficients: $Y=$
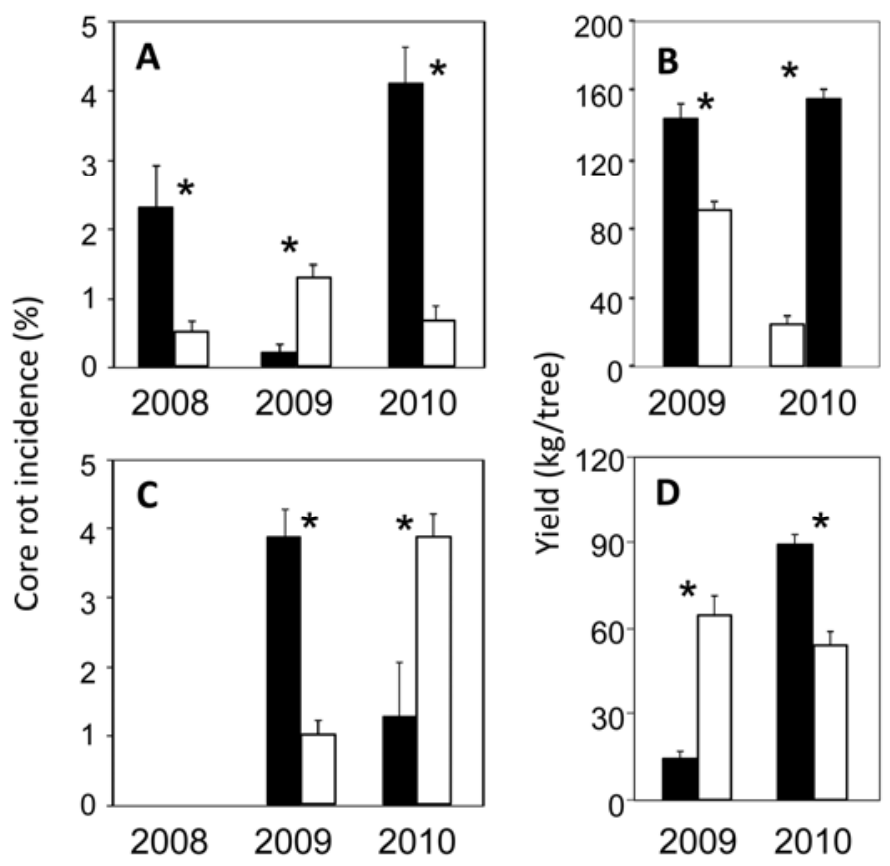

Fig. 4. Incidence of core rot and yield of two groups of trees growing in commercial orchards. The trees were assigned to two groups according to expected yield about 1 month before harvest in A and B, 2008 (observation O1) or C and D, 2009 (observation O2). Group A (filled bars): light-cropping trees; Group B (open bars): heavy-cropping trees. The same trees were sampled in subsequent years. Each group consisted of 10 to 20 trees; vertical bars represent the standard deviation of the mean. Asterisks indicate significant differences between the groups (at $P<0.05$ ) as determined by logistic regression analysis.
$0.05 \times e^{(160 /(X-31.4))}($ Fig. 7$)$. It turns out that the in-row tree spacing in the latter 3 orchards was different from that in the other orchards (1.2 to $1.8 \mathrm{~m}$ compared with 2.0 to $2.5 \mathrm{~m}$, respectively). For both equations, 63.1 and $75.5 \%$ of the variation in the incidence of core rot was explained by the yield load of the trees (Fig. 7).

Fruit size in individual trees was significantly affected by their yield load. On light-yielding trees, the proportion of large fruits was high and on heavy-yielding trees, the proportion of small fruits was high. Overall experiments, the regression between yield load $(X$, in $\mathrm{kg}$ per tree) and the proportion of large fruits $(Y$, in $\%)$ was $Y=70.3-0.5 X(P=0.0002)$. To examine whether fruit size affects the incidence of core rot, we quantified the relationship between the proportion of large fruits and the relative incidence of large fruits with core rot and that between the proportion of small fruits and the relative incidence of small fruits with core rot. We reasoned that if fruit size were not influencing core rot, data points for these relationships would probably shown more randomly against the 1:1 line. However, the relative incidence of large fruits with core rot was larger than the proportion of large
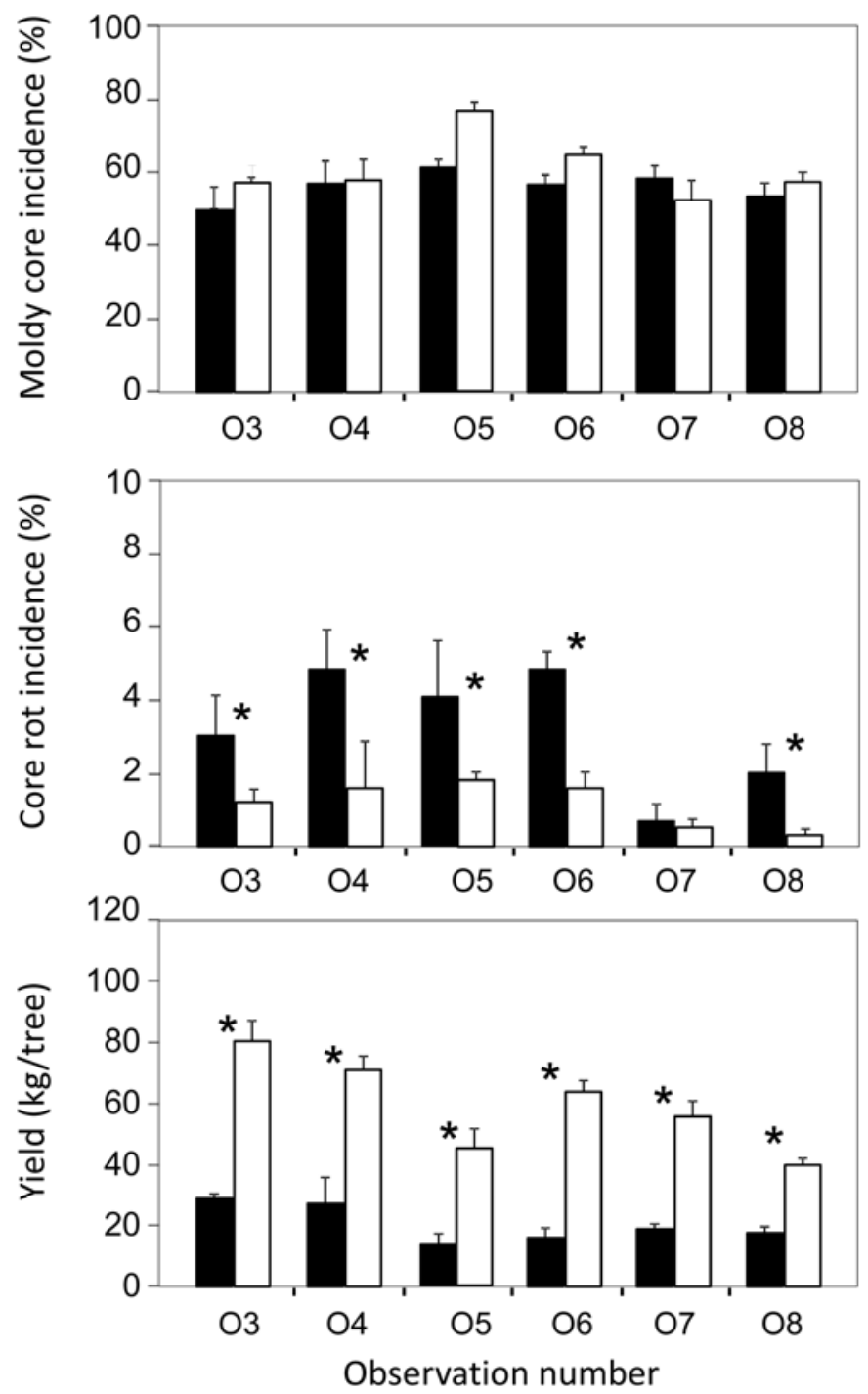

Fig. 5. Incidence of moldy core and core rot and yield of two groups of trees growing in six commercial orchards in northern Israel. The trees were assigned to two groups according to expected yield about 1 month before harvest in 2010. Group A (filled bars): light-cropping trees; Group B (open bars): heavy-cropping trees. Each group consisted of 10 trees; vertical bars represent the standard deviation of the mean. Asterisks indicate significant differences between the groups (at $P<0.05$ ) as determined by logistic regression analysis. 


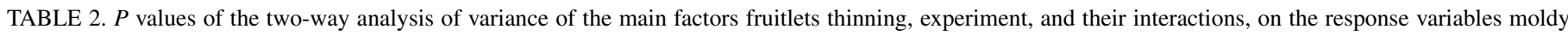
core incidence, core rot incidence and yield ${ }^{\mathrm{x}}$

\begin{tabular}{|c|c|c|c|}
\hline \multirow[b]{2}{*}{ Factor } & \multicolumn{3}{|c|}{ Response variable } \\
\hline & Moldy core incidence & Core rot incidence & Yield \\
\hline Fruitlet thinning ${ }^{\mathrm{y}}$ & 0.005 & 0.001 & $<0.0001$ \\
\hline Experiment $\mathrm{t}^{\mathrm{Z}}$ & 0.005 & 0.004 & 0.278 \\
\hline Fruitlet thinning $\times$ experiment & 0.749 & 0.196 & 0.042 \\
\hline
\end{tabular}

x Data are presented in Figure 6.

${ }^{y}$ Levels: 50, 100, 200, 300, and no thinning with about 500 fruits per tree.

${ }^{\mathrm{z}}$ Experiments E11 to E14. This factor was defined as random in the analyses.
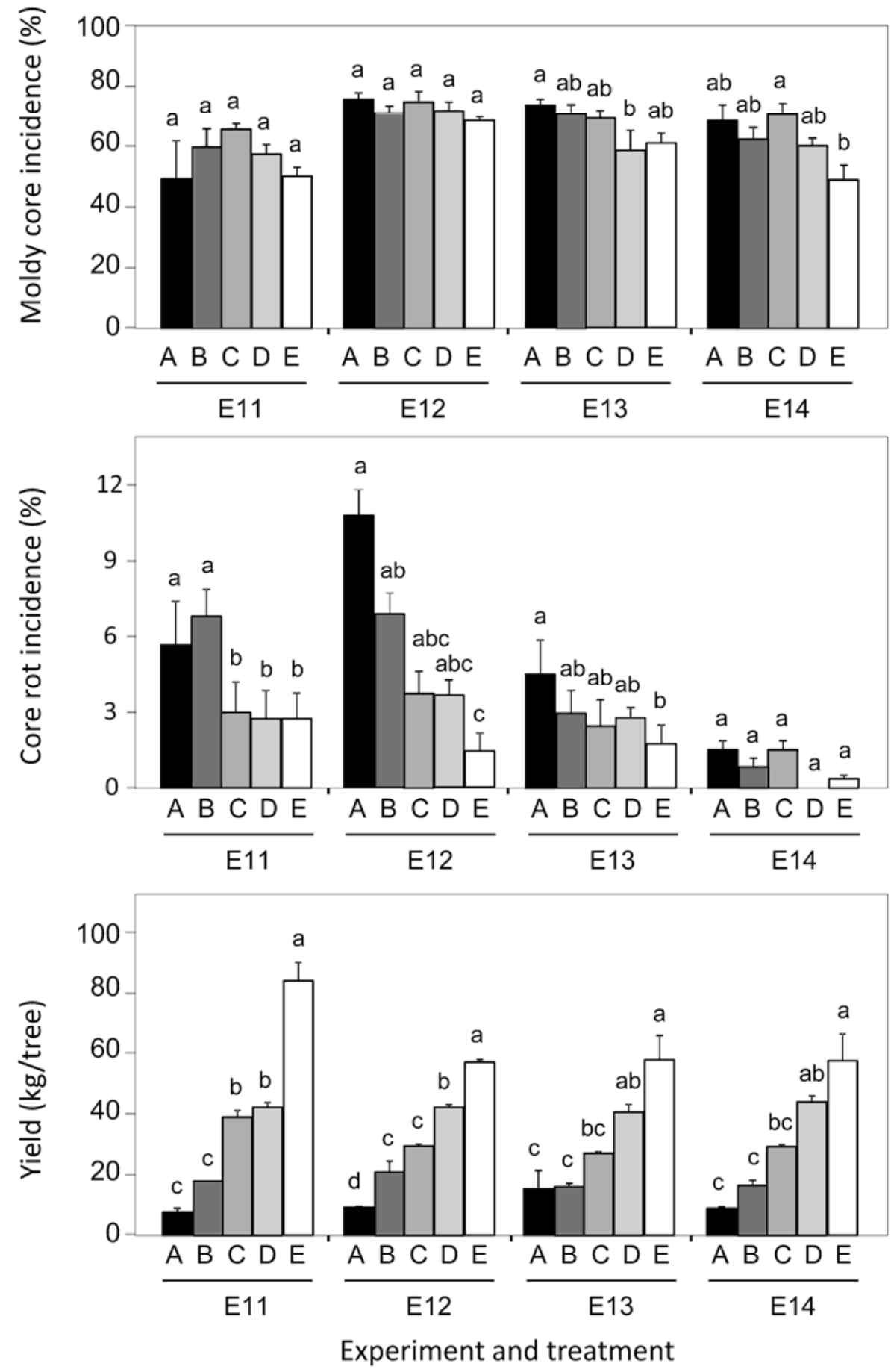

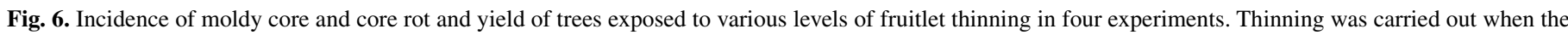

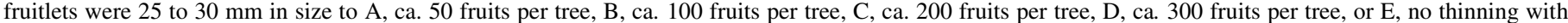

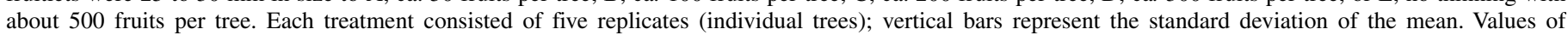
columns accompanied by different letters differ significantly (at $P \leq 0.05$ ) as determined by Tukey-Kramer protected honestly significantly different test. 
fruits $(62.9 \%$ of the data points were above the $1: 1$ line plus $5 \%$ compared with only $12.6 \%$ of the data points that were scattered below the 1:1 line minus 5\%; Fig. 8A). Similarly, the relative incidence of small fruits with core rot was less than the proportion of small fruits $(56.8 \%$ of the data points were scattered below the $1: 1$ line minus $5 \%$ as compared with only $10.3 \%$ that were scattered above the 1:1 line plus 5\%; Fig. 8B). For each group, these differences were significant at $P<0.001$ by $\chi^{2}$ test. These findings implied that in addition to yield load, fruit size also affects the susceptibility of the fruits to core rot such that the probability of core rot developing in large fruits is higher than that in small fruits.

\section{DISCUSSION}

Core rot is commonly considered to be the outcome of a chain of events. First, A. alternata colonizes the senescing flower parts during and shortly after bloom. Then, the pathogen moves through the open calycine tube into the receptacle or core region

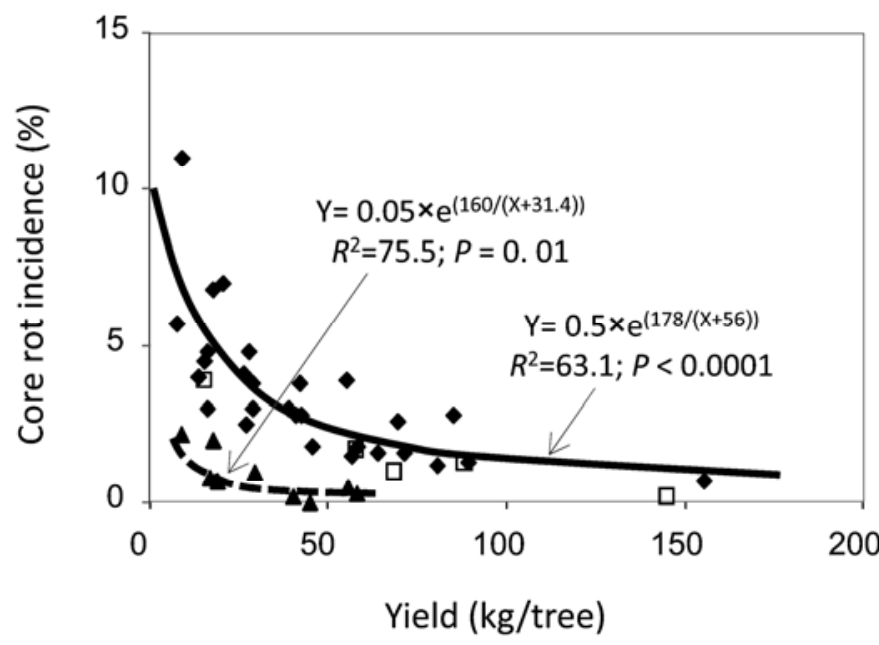

Fig. 7. Relationship between yield load and incidence of core rot. Data points represent individual treatments in 15 experiments and observations carried out in commercial orchards in 2009 (open symbols) and 2010 (filled symbols). Filled triangles and broken regression line denote to experiment E14, and observations $\mathrm{O} 4$ and $\mathrm{O} 7$ (Table 1). of the fruit, develops and causes moldy core. As the calycine tube remains open and the pathogen, A. alternata, is capable of developing saprophytically and sporulates abundantly on senescing tissues and organic matter in the orchard (26), lack of susceptible host tissue or virulent pathogen populations are presumably not limiting factors in the development of moldy core. Accordingly, variation in moldy core incidence among seasons and production regions most likely reflects differences in the suitability of the environmental conditions for infection. The pathogen then grows and fills the loculus, penetrates the seed locule walls and invades the mesoderm, inducing rot $(4,6,8,17,20,21,25,29,30,31)$. This process implies that core rot is governed by the suitability of environmental conditions to the pathogen and that core rot is directly related to the development of moldy core.

However, results of the present study appear to disagree, and in some respects contradict, our initial hypothesis and expectations based on the above chain of events. First, we could not find any evidence of prevailing environmental conditions during bloom affecting the development of moldy core or core rot. The incidence of fruits with moldy core was high, with low variability, in all experiments and observations irrespective of environmental conditions (Figs. 1, 3, 5, and 6), similar to results obtained by others $(10,20)$. Presumably, weather conditions in Israel during bloom do not limit the infection process or penetration of $A$. alternata into the seed cavity of the fruits. Furthermore, weather conditions do not appear to affect the development of core rot, as providing prolonged wetness by irrigating the trees at full bloom did not increase its incidence. The observation of large differences in core rot incidence among trees growing side by side in the same orchard, and the aggregated distribution of trees bearing fruits with core rot in the orchard preclude the possibility that environmental conditions affect core rot development. Temperature, wetness, rain and their interactions do not differ markedly at such small distances.

Second, several lines of evidence suggested that core rot development is not directly related to moldy core. Obviously, core rot could not have developed if the pathogen had not colonized the loculus; nevertheless, a high incidence of moldy core was not necessarily associated with a high incidence of core rot, or vice versa (Figs. 1, 3, 5, and 6). Moreover, in the 2010 experiments, thinning was performed when the fruitlets were 25 to $30 \mathrm{~cm}$ in diameter. At that time, the pathogen had already colonized the core region and differences in moldy core incidence among the
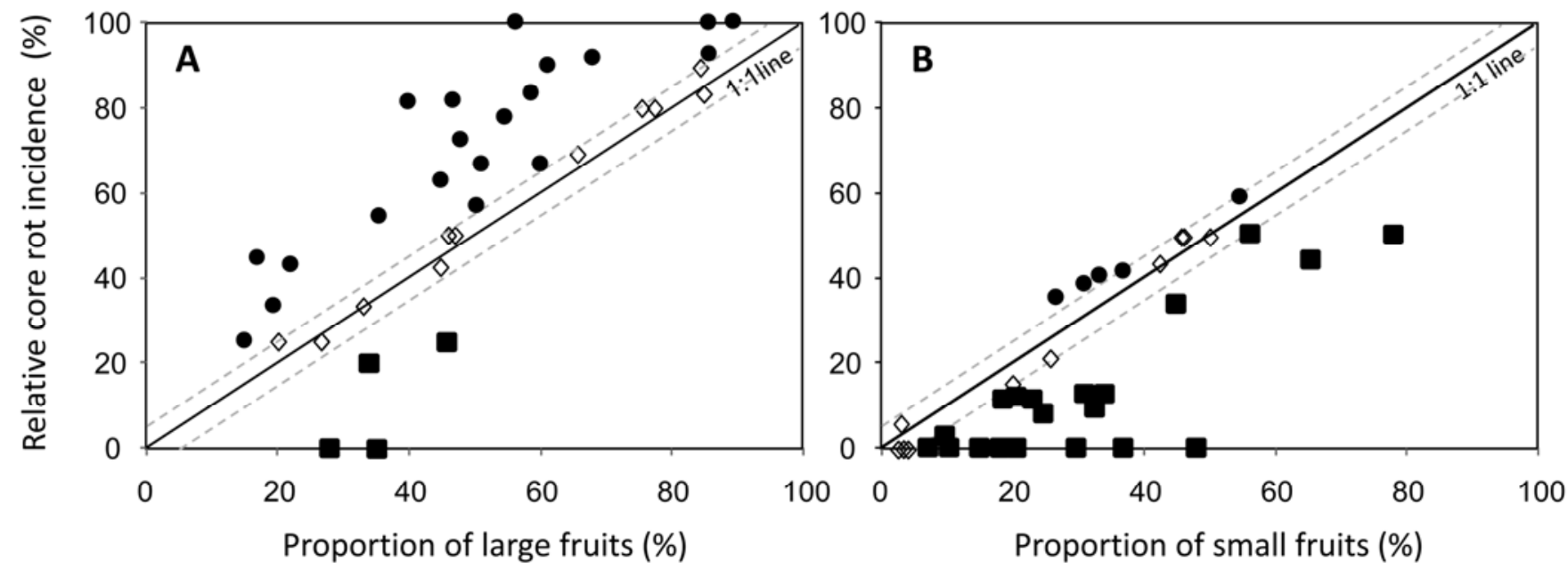

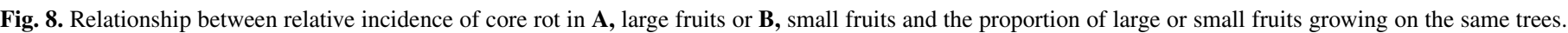

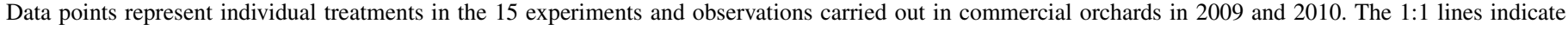

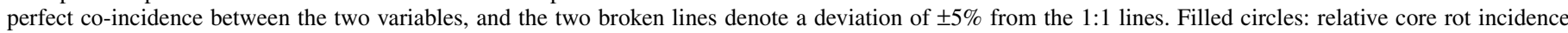

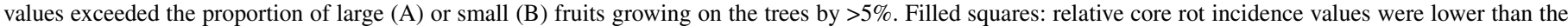

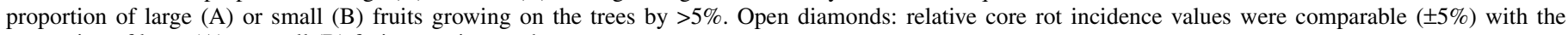
proportion of large $(\mathrm{A})$ or small $(\mathrm{B})$ fruits growing on the trees. 
treatments were insignificant. The fact that thinning affected core rot incidence (Fig. 6) suggests that factors other than actual colonization of the loculus govern its development.

Third, it was expected that frequent application of fungicide during bloom would reduce moldy core and subsequently, core rot. However, spraying had no significant effect. Several reasons might explain the inefficacy of the chemical treatment. The employed fungicides might not have been effective against $A$. alternata. However, these fungicides have been reported to be highly effective in previous studies $(22,23)$. The timing of the spraying might have been inappropriate. However, in treatment 2 of our experiments fungicides were applied three times a week, from first to last bloom, the period during which infections have been reported to occur $(6,17,20,25,30)$. The A. alternata isolates infecting the blossoms might have been resistant to the employed fungicides. This possibility cannot be discarded, but in our opinion, it is not likely: the likelihood of resistance developing simultaneously in all 10 experiments dispersed across a large geographical area is not high. Furthermore, a mixture of systemic and protectant fungicides (bromuconazole with captan) was applied, a common strategy for delaying resistance development (23). Finally, the sprays might have been improperly applied. Although this possibility cannot be discarded, the individual applying the sprays was highly qualified, with many years of experience in his profession. Thus, we do not know why spraying was not effective in all experiments. It should be noted that Red Delicious growers in Israel, who were used to spraying during bloom for suppression of core rot, have repeatedly reported on the ineffectiveness of the treatment, corroborating our results.

As fungicides had no effect on the incidence of moldy core or core rot, data recorded in the fungicide experiments reflected the spatial distribution of the disease under natural infections. The observed spatial aggregation of the trees with core rot further supported the conclusion that factors other than environmental conditions govern disease development. Niem et al. (20) studied the effects of the host on core rot development using 2 cultivars differing in their response to the disease: Red Delicious (susceptible) and Golden Delicious (resistant). They reported that the pathogen similarly colonized the style and ovary and developed in the mesoderm of the two cultivars. However, the two cultivars differed in the susceptibility of their seed locule walls to $A$. alternata invasion, and the authors speculated that this was the main difference between them. The basis for this difference is still unknown, but they listed several possibilities, among them tenderness/toughness of the epidermal layer, concentrations of polyphenols, lack of activation of fungal enzymes, acid content of the fruit and its resulting $\mathrm{pH}$ (20). Pursuant to their findings, we examined the mineral content of the locule walls in the two cultivars. The most noticeable difference was in the content of calcium, being $0.37 \pm 0.04 \%$ dry weight in the locule wall of Golden Delicious and $0.14 \pm 0.03 \%$ dry weight in the locule wall of Red Delicious (D. Shtienberg, unpublished data). Calcium was considered as one of the elements whose content in the locule wall might be related to the fruit's susceptibility to core rot, as calcium polygalacturonates are required in the middle lamella for cell-wall stability. A. alternata (like many other parasitic fungi) invades plant tissues by producing extracellular pectolytic enzymes such as polygalacturonase, which dissolve the middle lamella $(20,22)$. The activity of these enzymes is drastically inhibited by calcium $(2,9,32)$. Our observation of large variability in core rot incidence existing among trees of the same cultivar growing side by side in the same orchard suggests that in addition to host genetics, host physiology may also play a role at this pathosystem.

In one of the 2007 experiments, the incidence of core rot in light-yielding trees was found to be higher than in heavy-yielding ones. The hypothesis that core rot is governed by host physiology and that yield load can be used as an indicator of tree sus- ceptibility was initially examined in a set of eight observations, where variation in yield load among trees reflected the natural alternate bearing of yield and in another four experiments where variation in yield load was imposed by thinning. Thinning was performed when the fruitlets were 25 to $30 \mathrm{~cm}$ in size, thus the events leading to the development of core rot occurred, most likely, during, rather than prior to fruit development. In addition, we found that fruit size, irrespective of tree yield load, also affected the likelihood of core rot development: core rot was more abundant on large than on small fruits (Fig. 8). In a previous study, Spotts (30) showed that the incidence of core was related to the shape (length-diameter ratio) of fruits. This parameter was not examined in the current study.

An alternate bearing tree yields a heavy crop in one year ('onyear') followed by a light crop in the following year ('off-year'), and so on (18). Alternate bearing can be triggered in two ways. The alternation can develop gradually, in relation to the annual increase in yield during the first years of fruiting, allowing the coexistence of 'on' and 'off' trees in the same year. Alternatively, and perhaps more often, a single environmental event, usually climatic but occasionally pest-related, leads to abrupt, extreme alternation. In such cases, the alternate bearing is synchronized for the whole orchard and in most cases, for the entire region. Following an extreme 'on' year with profuse flowering, heavy fruiting occurs with almost no vegetative growth, leading to a shortage of flowering sites with potential for the next year's crop (18). Generally, light-cropping in apple concurs with excessive shoot growth, increased fruit size and lower fruit calcium concentration. The reduced calcium concentration in fruits growing on trees with excessive shoot growth has been attributed to stronger competition for available calcium between fruits and the new vigorous shoots with heavy foliage at the most critical time for fruit development $(13-15,27,28)$. In heavy-cropping trees, fruits are usually relatively small but have high calcium concentrations, which show an average decline in proportion with increasing fruit size. In apples from light-yielding trees, calcium concentration is lower in all size classes compared with apples from trees with high crop load $(11,12)$.

More than 35,000 fruits were harvested, cut, inspected and scored in the 16 experiments and eight observations performed during the 4 years of this study. This vast effort exemplifies the importance that the apple industry, financing the research, attributes to the core rot problem. Based on the results, we suggest a shift in research priorities from quantifying the effects of environmental conditions on the infection process and developing means for controlling A. alternata, to exploring the mechanisms by which the physiological status of the host plant governs the development of core rot and developing means for enhancing the resistance of the fruit's locule wall to pathogen invasion. In our opinion, understanding these mechanisms is the key to developing effective, environmentally friendly means for adequately coping with core rot disease.

\section{ACKNOWLEDGMENTS}

This research was supported by The Plants Production and Marketing Board and by Northern R\&D. The contribution of U. Yermiyahn, Y. Doron, S. Kfir, A. Moshe, and E. Yonai is greatly appreciated.

\section{LITERATURE CITED}

1. Archer, C. 2002. The use of honeybees as a transfer vector for core rot in apples. Publication No. 02/046 RIRDC Project No TAR-1A. Rural Industries Research and Development Corporation. Barton, Kingston, Australia.

2. Bateman, D. F., and Lumsden, R. D. 1965. Relation between calcium content and nature of the peptic substances in bean hypocotyls of different ages to susceptibility to an isolate of Rhizoctonia solani. Phytopathology 55:734-738. 
3. Biggs, A. R., Ingle, M., and Solihati, W. D. 1993. Control of Alternaria infection of fruit of apple cultivar Nittany with calcium chloride and fungicides. Plant Dis. 77:976-980.

4. Brown, E. A., and Hendrix, F. F. 1978. Effect of certain fungicides sprayed during apple bloom on fruit set and fruit rot. Plant Dis. Rep. 62:739-741.

5. Combrink, J. C., and Ginsberg, L. 1973. Core rot in Starking apples a preliminary investigation into the origin and control. Deciduous Fruit Grower 23:16-19.

6. Combrink, J. C., Kotze, J. M., and Visagie, T. R. 1985. Colonisation of apples by fungi causing core rot. Hort. Sci. 2:9-13.

7. Combrink, J. C., Visagie, T. R., and Grobbelaar, C. C. 1984. Variation in the incidence and occurrence in different production areas of core rot in Starking apples. Deciduous Fruit Grower 34:88-89.

8. De Kock, S. L., Visagie, T. R., and Combrink, J. C. 1991. Control of core rot in Starking apples. Deciduous Fruit Grower 41:20-22.

9. Elad, Y., and Evensen, K. 1995. Physiological aspects of resistance to Botrytis cinerea. Phytopathology 85:637-643.

10. Ellis, M. A., and Barrat, J. G. 1983. Colonisation of Delicious apple fruits by Alternaria spp. and effect of fungicide sprays on mouldy core. Plant Dis. 67:150-152.

11. Ferguson, I. B., and Triggs, C. M. 1990. Sampling factors affecting the use of mineral analysis of apple fruit for the prediction of bitter pit. N.Z. J. Crop Hort. Sci. 18:147-152.

12. Ferguson, I. B., and Watkins, C. B. 1992. Crop load affects mineral concentrations and incidence of bitter pit in 'Cox's Orange Pippin' apple fruit. J. Am. Soc. Hort. Sci. 117:373-376.

13. Garman, P., and Mathis, W. T. 1956. Studies of mineral balance as related to the occurrence of Baldwin spot in Connecticut. Bull. Connecticut Agric. Exp. Stn. 601:1-19.

14. Greene, D. W. 1991. Reduced rates and multiple sprays of paclobutrazol control growth and improve fruit quality of 'Delicious' apples. J. Am. Soc. Hort. Sci. 116:807-812.

15. Greene, D. W., and Lord, W. J. 1983. Effects of dormant pruning, summer pruning, scoring, and growth regulators on growth, yield, and fruit quality of 'Delicious' and 'Cortland' apple trees. J. Am. Soc. Hort. Sci. 108:590-595.

16. Little, C. R., and Holmes, R. J. 2000. Storage technology for apples and pears. Department of Natural Resources and Environment, Victoria, Australia.

17. Miller, P. M. 1959. Open calyx tubes as a factor contributing to carpel discoloration and decay of apples. Phytopathology 49:520-523.

18. Monselise, S. P., and Goldschmidt, E. E. 1982. Alternate bearing in fruit trees. Hort. Rev. 4:128-173.
19. Morisita, M. 1962. $I_{\delta}$ - index, a measure of dispersion on individuals. Res. Popul. Ecol. 4:1-7.

20. Niem, J., Miyara, I., Ettedgui, Y., Reuveni, M., Flaishman, M., and Prusky, D. 2007. Core rot development in red delicious apples is affected by susceptibility of the seed locule to Alternaria alternata colonization. Phytopathology 97:1415-1421.

21. Pierson, C. F., Ceponis, M. J., and McColloch, L. P. 1971. Market diseases of apples, pears and quinces. U.S. Dep. Agric. Agriculture Handbook 376. Gov. Printer, Washington DC.

22. Reuveni, M. 2006. Inhibition of germination and growth of Alternaria alternata and mouldy-core development in Red Delicious apple fruit by Bromuconazole and Sygnum. Crop Prot. 25:253-258.

23. Reuveni, M., and Prusky, D. 2007. Improved control of moldy-core decay (Alternaria alternata) in Red Delicious apple fruit by mixtures of DMI fungicides and captan. Eur. J. Plant Pathol. 118:349-357.

24. Reuveni, M., Sheglov, N., Eshel, D., Prusky, D., and Ben-Arie, R. 2006. Virulence and the production of endo-1,4- $\beta$-glucanase by isolates of Alternaria alternata involved in the moldy-core disease of apples. J. Phytopathol. 155:50-55.

25. Reuveni, M., Sheglov, D., Sheglov, N., Ben-Arie, R., and Prusky, D. 2002. Sensitivity of Red Delicious apple fruit at various phenologic stages to infection by Alternaria alternata and moldy-core control. Eur. J. Plant Pathol. 108:421-427.

26. Rotem, J. 1994. The Genus Alternaria: Biology, Epidemiology, and Pathogenicity. American Phytopathology Society, St. Paul, MN.

27. Sharples, R. O. 1974. The number and size of fruits in relation to rootstock type, application of growth regulators, pruning, and fruit thinning. Acta Hort. 45:21-24.

28. Shear, C. B. 1980. Interaction of nutrition and environment on mineral composition of fruits. Pages 41-50 in: Mineral Nutrition of Fruit Trees. D. Atkinson, J. E. Jackson, R. O. Sharples, and W. M. Waller, eds. Butterworths, London.

29. Snowdon, A. L. 1991. Pages 171-200 in: A Colour Atlas of Post Harvest Diseases and Disorders of Fruit and Vegetables, Vol. 1. Academic Press, CA.

30. Spotts, R. A. 1990. Moldy core and core rot. Pages 29-30 in: Compendium of Apple and Pear Diseases. A. L. Jones and H. S. Aldwinckle, eds. American Phytopathology Society, St. Paul, MN.

31. Spotts, R. A., Holmes, R. J., and Washington, W. S. 1988. Factors affecting wet core rot of apples. Austral. Plant Pathol. 17:53-57.

32. Taiz, L., and Zeiger, E. 2002. Mineral nutrition. Pages 67-86 in: Plant Physiology, 3rd ed. L. Taiz and E. Zeiger, eds. Sinauer Associates, Inc., Sunderland, MA. 